\title{
Cycloartobiloxanthone Induces Human Lung Cancer Cell Apoptosis via Mitochondria-dependent Apoptotic Pathway
}

\author{
NATTANAN LOSUWANNARAK ${ }^{1,2}$, BOONCHOO SRITULARAK $^{3}$ and PITHI CHANVORACHOTE ${ }^{1,2}$ \\ ${ }^{1}$ Department of Pharmacology and Physiology, \\ ${ }^{2}$ Cell-based Drug and Health Product Development Research Unit, \\ and ${ }^{3}$ Department of Pharmacognosy and Pharmaceutical Botany, \\ Faculty of Pharmaceutical Sciences, Chulalongkorn University, Bangkok, Thailand
}

\begin{abstract}
Background: Lung cancer is one of most malignant types of cancer and new anticancer agents are still required. Cycloartobiloxanthone, a flavonoid isolated from stem bark of Artocarpus gomezianus, has potential for being developed for anticancer therapy. Materials and Methods: Cytotoxicity of cycloartobiloxanthone was evaluated by 3(4,5-dimethylthiazol-2-yl)-2,5 diphenyltetrazolium bromide (MTT) assay against four human lung cancer cell lines (H23, H460, H292 and A549) and their half-maximal inhibitory concentrations $\left(I_{50}\right)$ were assessed. Apoptotic induction in H460 cells was investigated by Hoechst 33342/propidium iodide (PI) staining assay and protein hallmarks of mitochondria-dependent apoptotic pathway were examined by western blot analysis. Results: Cycloartobiloxanthone exhibited potent cytotoxic effect on both small and non-small cell lung cancer cells. Nuclear Hoechst/PI staining revealed that apoptotic cell death was the main mechanism of toxicity of cycloartobiloxanthone. The apoptosis-inducing potency of cycloartobiloxanthone was comparable to those of standard anticancer drugs cisplatin and etoposide at the same concentration. Protein analysis further showed that apoptosis was mediated via mitochondria-dependent pathway. p53 was activated in cells treated with cycloartobiloxanthone. Subsequently, pro-apoptotic protein B-cell lymphoma 2 (BCL2)-associated $X$ protein (BAX) was found to be
\end{abstract}

This article is freely accessible online.

Correspondence to: Pithi Chanvorachote, Ph.D., Department of Pharmacology and Physiology, Faculty of Pharmaceutical Sciences, and Cell-based Drug and Health Product Development Research Unit, Chulalongkorn University, Bangkok, Thailand. Tel: +662 2188285, Fax: +662 2188340, e-mail: pithi_chan@yahoo.com

Key Words: Cycloartobiloxanthone, lung cancer, apoptosis, mitochondria-dependent apoptotic pathway, BAX, MCL1. significantly increased, concomitantly with the decrease of anti-apoptotic proteins BCL2 and myeloid cell leukemia 1 (MCL1). Moreover, markers of the intrinsic apoptosis pathway, namely activated caspase-9, activated caspase-3, and cleaved poly(ADP-ribose)polymerase (PARP), dramatically increased in cycloartobiloxanthone-treated cells compared to the non-treated controls. Conclusion: Cycloartobiloxanthone has anticancer activity against human lung cancer cells by triggering mitochondrial apoptotic caspase-dependent mechanism. This compound might have promising effects for cancer therapy.

Lung cancer is recognized as the first cause of cancer-related death among all cancer types (1). Lung cancers are classified as small cell or non-small cell carcinomas according to whether they are non-epithelial or epithelial-derived, respectively. Currently, treatments for lung cancer are primarily surgical excision supplemented by radiation and chemotherapy. In terms of chemotherapy, cisplatin is a firstline chemotherapy used for both small cell and non-small cell lung cancer, with or without combination drugs such as etoposide or paclitaxel. Although these drugs have good efficacy against lung cancer, relapse and chemotherapy resistance occur (2) and remains a worldwide problem.

Discovery of novel anticancer drugs is needed and many interesting plant extracts have been studied for their anticancer effects $(3,4)$. Natural product-derived compounds have long been a major source for pharmacologically active compounds. Cycloartobiloxanthone (Figure 1), a flavonoid extracted from stem bark of Artocarpus gomezianus Wall. ex Tréc. (Moraceae), which is a tree widely distributed throughout Thailand locally known as "Hat-nun"(5), has been investigated for its possible pharmacological activities (5-7). However, to our knowledge, there are no reports about its anticancer activity against human lung cancer cells. The present study aimed to investigate the effects of this compound and its mechanism of actions against lung cancer cells. 


\section{Materials and Methods}

Cells and reagents. Human-derived lung cancer cell lines H460, H292, A549, H23 and human keratinocyte cell line HaCaT were obtained from the American Type Culture Collection (Manassas, VA, USA). The cells were cultured in Roswell Park Memorial Institute 1640 (RPMI-1640) or Dulbecco's modified Eagle's medium (DMEM) supplemented with $10 \%$ fetal bovine serum (FBS), $2 \mathrm{mM} \mathrm{L-}$ glutamine and 100 units $/ \mathrm{ml}$ of each penicillin and streptomycin (Gibco, Waltham, MA, USA) at $37^{\circ} \mathrm{C}$ with $5 \% \mathrm{CO}_{2}$ in a humidified incubator. 3-(4,5-Dimethylthiazol-2-yl)-2,5 diphenyltetrazolium bromide (MTT), dimethyl sulfoxide (DMSO), Hoechst 33342, propidium iodide (PI), and bovine serum albumin (BSA) were purchased from Sigma Chemical, Inc. (St. Louis, MO, USA). Antibodies directed against caspase-3, caspase-9, poly (ADP-ribose) polymerase (PARP), B-cell lymphoma 2-associated X (BAX), myeloid cell leukemia 1 (MCL-1), B-cell lymphoma 2 (BCL2), $\beta$ actin, and their respective secondary antibodies were purchased from Cell Signaling (Danvers, MA, USA). Cycloartobiloxanthone extracted from the stem bark of Artocarpus gomezianus was obtained from Pharmacognosy and Pharmaceutical Botany department, the Faculty of Pharmaceutical Sciences, Chulalongkorn University, Thailand.

Cell viability assay. As described elsewhere, the MTT assay was performed to determine the cytotoxic effect of cycloartobiloxanthone on lung cancer cells. Lung cancer cells (H460, H292, A549 and $\mathrm{H} 23$ ) were seeded at a density of $1 \times 10^{4}$ cells/well in 96-well plates and incubated overnight to allow the cells to attach to the plates. Next, the medium was removed and fresh medium with different concentrations of cycloartobiloxanthone $(0-100 \mu \mathrm{M})$ was added to the cells. After $24 \mathrm{~h}$ of treatment, the media were aspirated and the cells were incubated with MTT ( $400 \mu \mathrm{g} / \mathrm{ml}$ in $1 \times$ PBS) for 4 $\mathrm{h}$ at $37^{\circ} \mathrm{C}$, after which the supernatant solution was removed and 100 $\mu 1$ DMSO was added to dissolve the resulting formazan crystals. The formazan intensity was measured by spectrophotometry at $570 \mathrm{~nm}$ using a microplate reader (Perkin Elmer, Waltham, MA, USA). The percentage of cell viability was calculated as the absorbance of treated cells relative to that of untreated cells.

Nuclear staining assay. Cells were seeded in 96-well plates at a density of $1 \times 10^{4}$ cells/well, incubated overnight, and treated with cycloartobiloxanthone $(0-50 \mu \mathrm{M})$ for $24 \mathrm{~h}$. Hoechst $33342(10 \mu \mathrm{g} / \mathrm{ml})$ and PI $(5 \mu \mathrm{g} / \mathrm{ml})$ were added for $30 \mathrm{~min}$. Nuclear condensation and DNA fragmentation of apoptotic cells and PI-positive necrotic cells were visualized and scored using a phase-contrast and fluorescence microscope (Nikon eclipse Ts2; 40×) equipped with a Nikon's DSFi3 digital camera system (Nikon, Tokyo, Japan).

Western blot analysis. $\mathrm{H} 460$ cells were treated with $0,10,20,50 \mu \mathrm{M}$ of cycloartobiloxanthone for $24 \mathrm{~h}$. The cells were then incubated with lysis buffer containing $20 \mathrm{mM}$ Tris- $\mathrm{HCl}(\mathrm{pH} 7.5), 1 \%$ Triton X$100,150 \mathrm{mM}$ sodium chloride, $10 \%$ glycerol, $1 \mathrm{mM}$ sodium orthovanadate, $50 \mathrm{mM}$ sodium fluoride, $100 \mathrm{mM}$ phenylmethylsulfonyl fluoride and protease inhibitor cocktail (Theera Trading, Bangkokyai, BKK, Thailand) for $30 \mathrm{~min}$ on ice. The cellular lysates were collected by scraping and their protein content was determined using a BCA protein assay kit (Pierce Biotechnology, Rockford, IL, USA). The resultant lysates were added to Laemmli loading buffer and boiled at $95^{\circ} \mathrm{C}$ for $5 \mathrm{~min}$. Equal amounts of protein from each sample were separated by sodium dodecyl sulfate-polyacrylamide

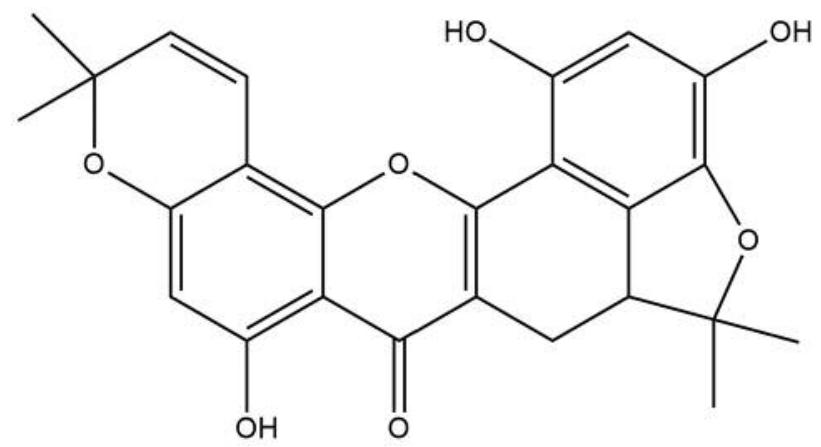

Figure 1. Structure of cycloartobiloxanthone.

gel electrophoresis and transferred to $0.45 \mu \mathrm{m}$ nitrocellulose membranes (Bio-Rad, Pathumwan, BKK, Thailand). The resulting blots were blocked for $1 \mathrm{~h}$ with $5 \%$ non-fat dry milk in Tris-buffer saline with $0.1 \%$ Tween containing $25 \mathrm{mM}$ Tris- $\mathrm{HCl}$ (pH 7.5), 125 $\mathrm{mM} \mathrm{NaCl}$ and $0.1 \%$ Tween 20 (TBST) and incubated with the primary antibodies listed above at $4{ }^{\circ} \mathrm{C}$ overnight. After three washes in TBST, the blots were incubated with horseradish peroxidaseconjugated secondary antibodies for $2 \mathrm{~h}$ at room temperature. Finally, protein bands were detected using an enhancement chemiluminescence substrate (Supersignal West Pico; Pierce) and quantified using ImageJ $1.51 \mathrm{j} 8$ software (National Institutes of Health, Bethesda, MD, USA).

Statistical analysis. Data from three or more independent experiments were presented as the mean \pm standard deviation (SD). Multiple comparisons for significant differences between multiple groups were performed using analysis of variance (ANOVA), followed by individual comparisons with Scheffe's post-hoc test. Statistical significance was considered at $p<0.05$.

\section{Results}

Cytotoxic effect of cycloartobiloxanthone on human lung cancer cells. Anticancer activity of cycloartobiloxanthone (Figure 1) was first assessed in four types of human lung cancer cells. The human lung cancer H460, H292, A549 and $\mathrm{H} 23$ cells were seeded and treated with different concentrations (0-100 $\mu \mathrm{M})$ of cycloartobiloxanthone for $24 \mathrm{~h}$. The cell viability of treated and non-treated groups was evaluated by MTT assay. As shown in Figure 2, a significant decrease in cell viability of all cell types were observed in response to the treatment of cycloartobiloxanthone at $20 \mu \mathrm{M}$. The $\mathrm{IC}_{50}$ of this compound against H460, H292, A549 and H23 cells was $59.19,49.56,110.93$ and $91.19 \mu \mathrm{M}$, respectively $(\mathrm{n}=3)$.

Apoptotic cell death induced by cycloartobiloxanthone. Having shown the cytotoxic effect of cycloartobiloxanthone on human lung cancer cells, we next determined the mechanism of cell death induced by the compound and the mode of cell death, whether apoptosis or necrosis, was further 


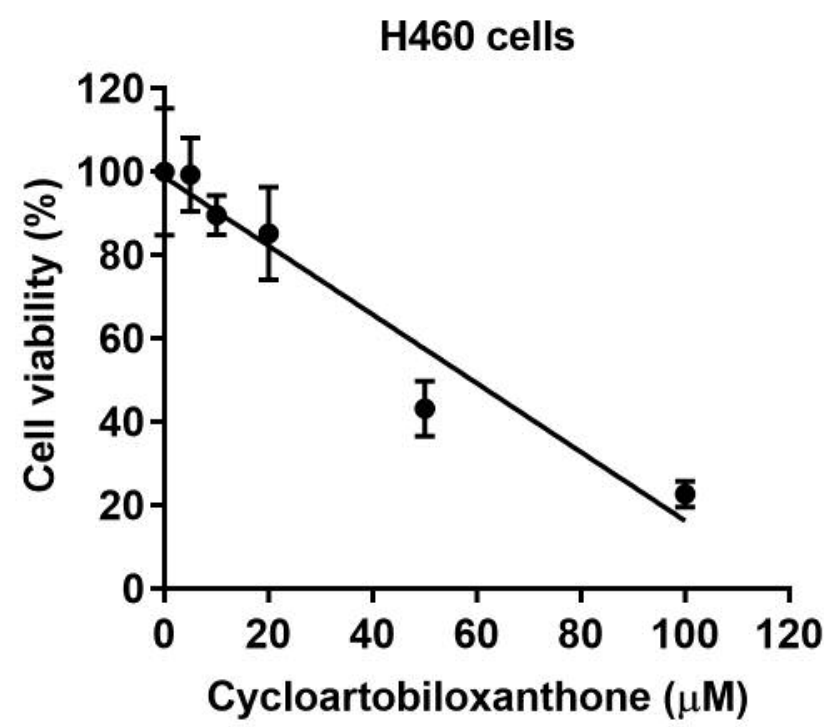

A549 cells

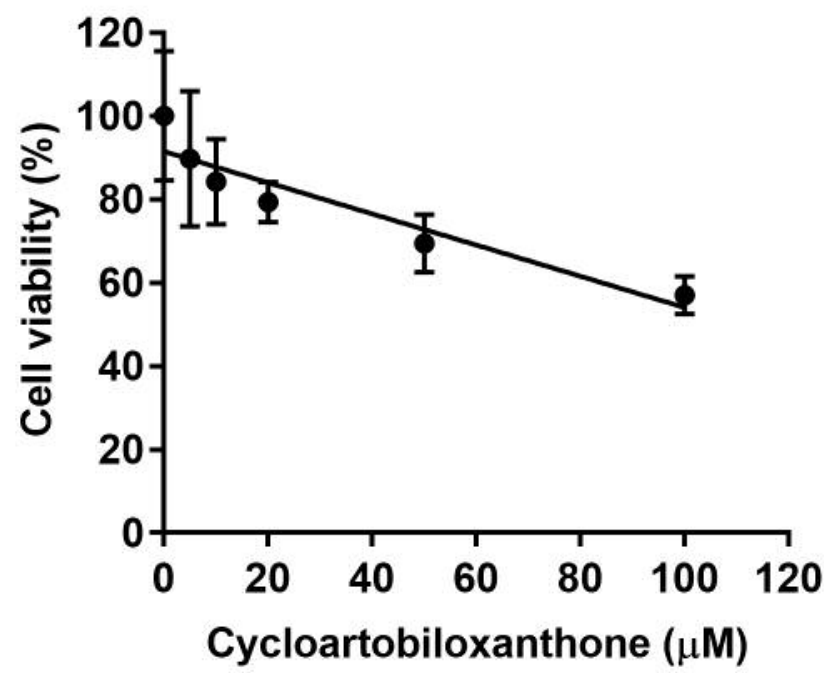

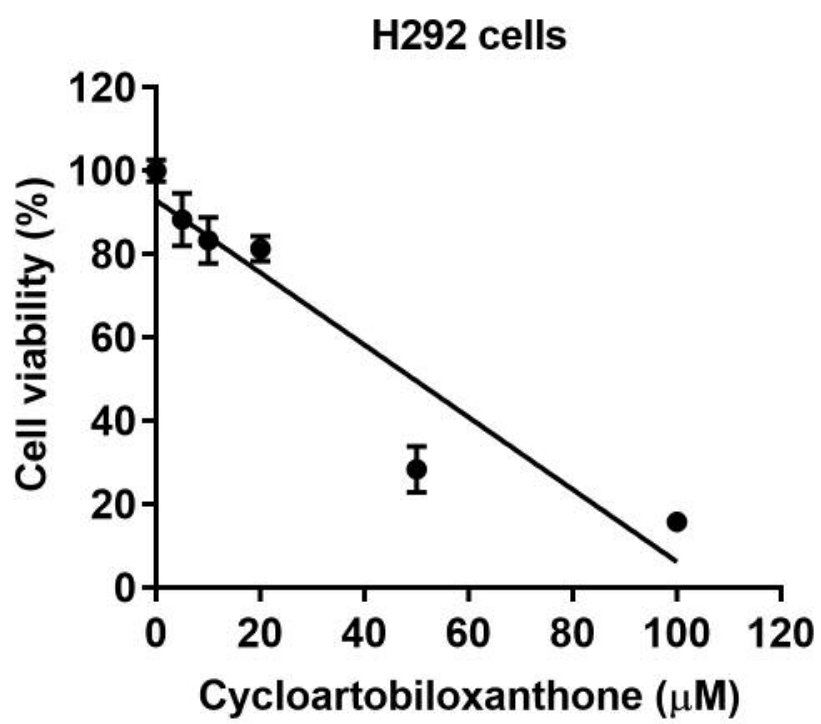

H23 cells

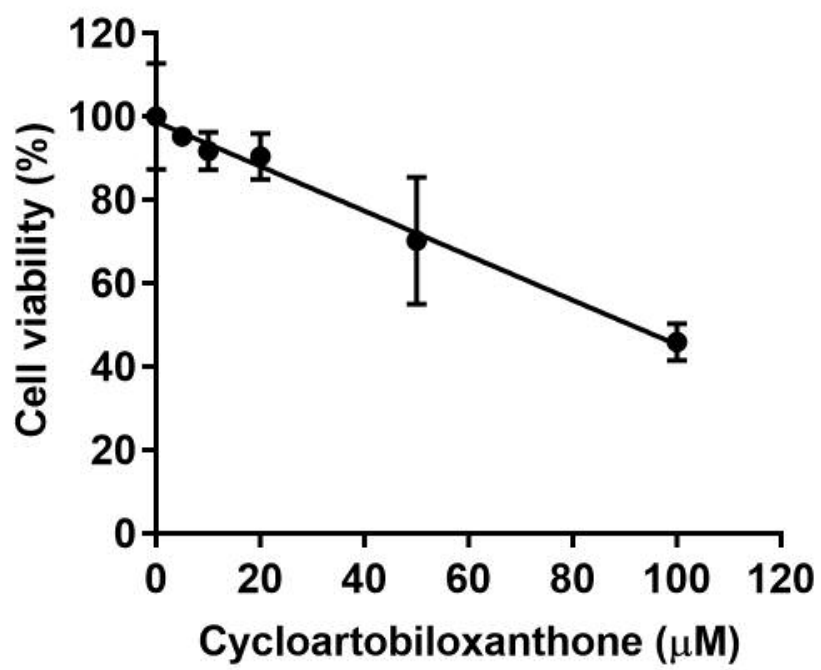

\begin{tabular}{|c|c|}
\hline Cell & IC $_{50}(\boldsymbol{\mu} \mathbf{M})$ \\
\hline H460 & 59.19 \\
\hline H292 & 49.56 \\
\hline A549 & 110.93 \\
\hline H23 & 91.19 \\
\hline
\end{tabular}

Figure 2. Cytotoxic effect of cycloartobiloxanthone on H460, H292, A549 and H23 cancer cells. Each cell lines were treated with 0-100 $\mu$ M of cycloartobiloxanthone for $24 \mathrm{~h}$. Cell viability was analyzed by 3-[4,5-dimethylthiazol-2-yl]-2,5 diphenyltetrazolium bromide assay. Data was presented as mean $\pm S D(n=3)$. The half maximal inhibitory concentration $\left(I C_{50}\right)$ of each cell line was calculated.

investigated by Hoechst33342/PI nuclear co-staining. The non-treated H460 control cells exhibited normal intact cell morphology and adhered firmly to the culture surface with no cell debris under phase-contrast microscope. In contrast, cycloartobiloxanthone-treated cells exhibited rounded shape and detached from the plate with the formation of apoptotic bodies. Further examination of Hoechst/PI co-stained cells under fluorescent microscopy showed that the 

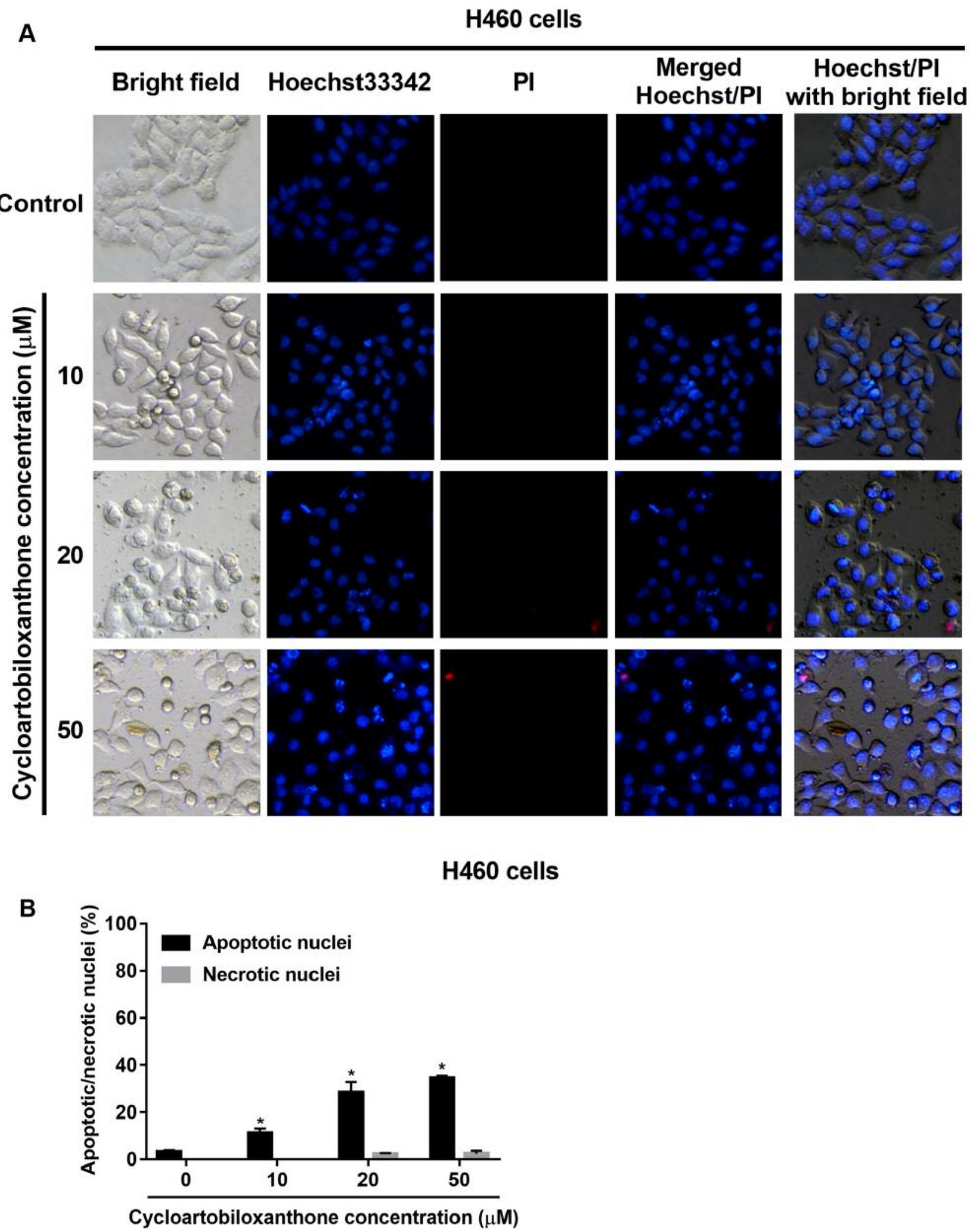

Figure 3. A: Apoptotic and necrotic cell death after $24 \mathrm{~h}$ of cycloartobiloxanthone treatment were examined by Hoechst 33342/propidium iodide (PI) co-staining. B: Percentage of apoptotic and necrotic nuclei in cycloartobiloxanthone-treated cells. Data are presented as the mean $\pm S D(n=3)$. *Significantly different at $p<0.05$ compared to the untreated control group. 
A

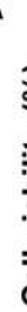

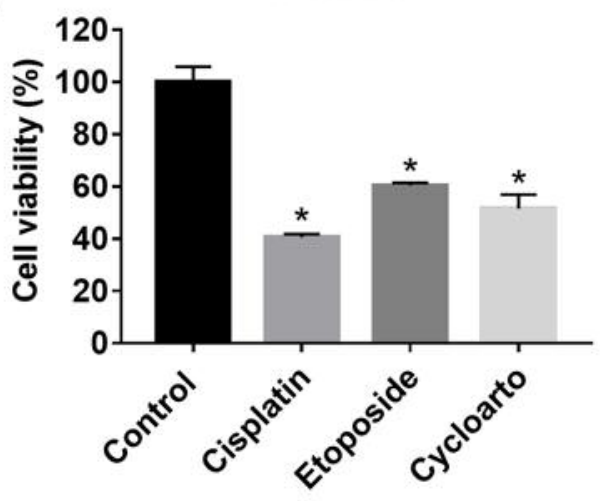

B

Control

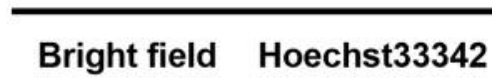

H460 cells
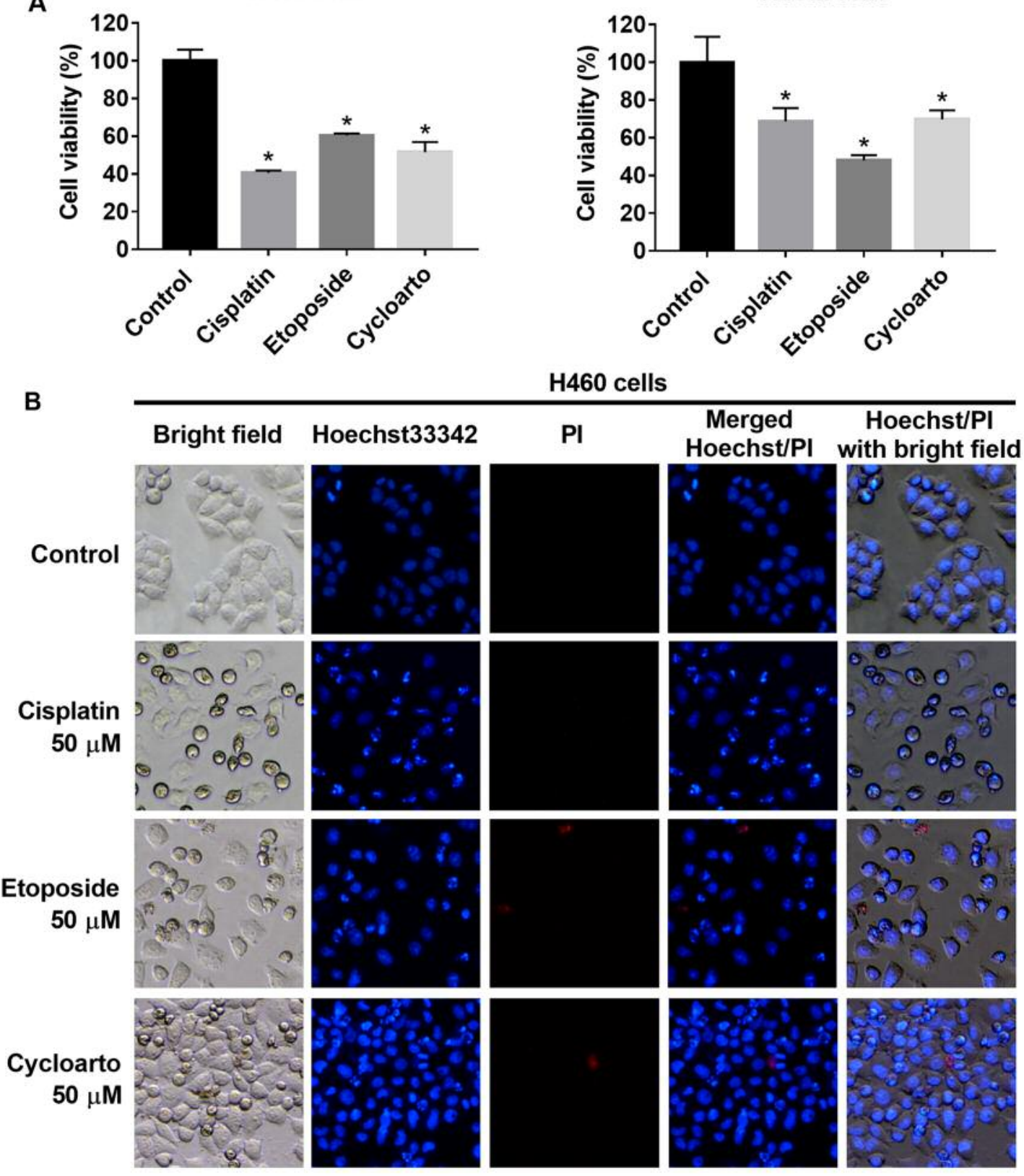

H460 cells

C

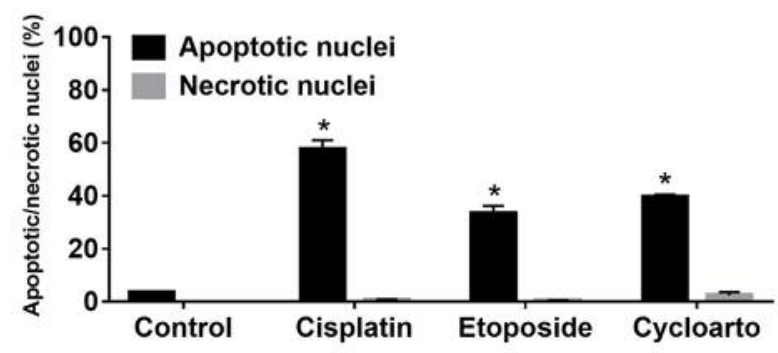

Figure 4. A and B: Apoptotic and necrotic cell death after 24 h of $50 \mu M$ cisplatin, etoposide and cycloartobiloxanthone treatments were examined by Hoechst 33342/propidium iodide (PI) co-staining. C: Percentage of apoptotic and necrotic nuclei in each treatment group. Data are presented as the mean $\pm S D(n=3)$. *Significantly different at $p<0.05$ compared to the untreated control group. 
A

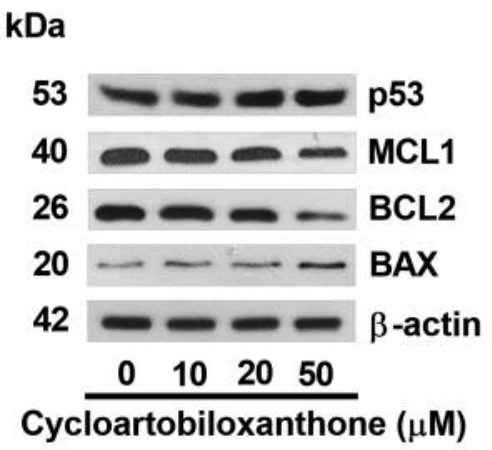

B

\section{H460 cells}

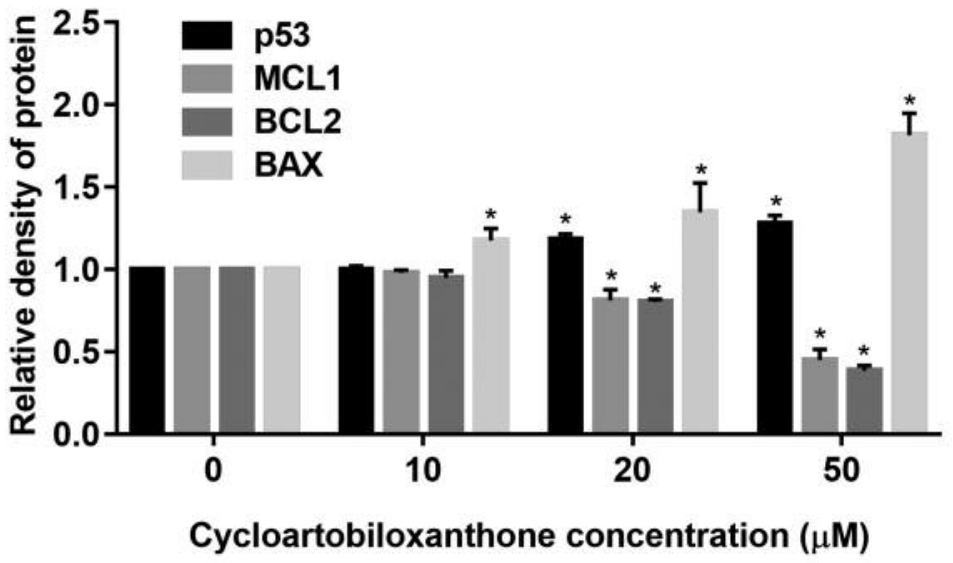

H460 cells

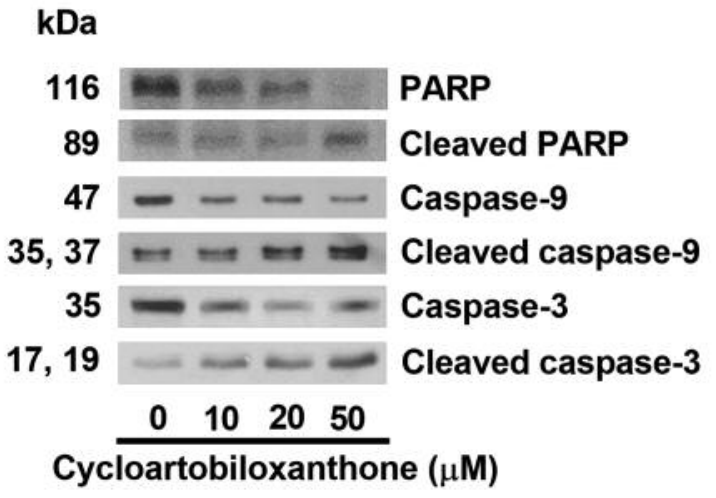

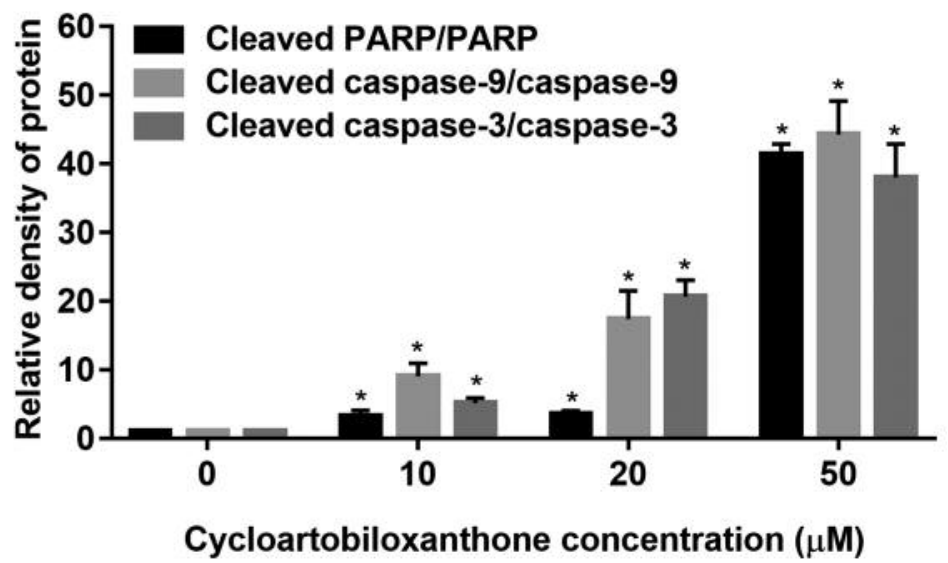

Figure 5. Western blot analysis of proteins involved in mitochondria-mediated apoptotic cell death. H460 cells were treated with different doses of cycloartobiloxanthone for $24 \mathrm{~h}$. B: Relative protein levels were quantified by densitometry. Data represent the mean $\pm S D(n=3)$. ${ }^{*}$ Significantly different at $p<0.05$ compared to the untreated control group.

cycloartobiloxanthone-treated cells exhibited obvious characteristics of apoptosis (Figure 3). Apoptotic cells were indicated by bright blue dots of condensed/fragmented nuclei compared to other dimly blue-stained nuclei, which represented the intact cells. Necrotic cells were characterized by red spots of PI staining. PI cannot pass through intact cell membranes, unless there is any damage leading to loss of membrane permeability. However, late-apoptotic cells may be stained by PI, hence we confirmed the results by observing the cell morphology through merged images of Hoechst and PI staining (Figure 3A). The percentage of apoptotic and necrotic cells found under fluorescence microscopy were consistent with the MTT results and we concluded that cell death caused by cycloartobiloxanthone was mainly due to apoptosis. It is noteworthy that cycloartobiloxanthone rarely induced necrosis even at high concentrations (Figure 3B).

Cytotoxic effect of cycloartobiloxanthone in comparison to standard anticancer drugs. Cisplatin and etoposide were long used as anti-cancer agents for the treatment of lung cancer. Here we used cisplatin and etoposide as positive controls. Cell viability MTT assay and Hoechst 33342/PI nuclear co-staining were used to evaluate the potency of cycloartobiloxanthone. Cells were treated with the same dose $(50 \mu \mathrm{M})$ of cisplatin, etoposide or cycloartobiloxanthone for $24 \mathrm{~h}$ and subjected to cell viability, apoptosis, and necrosis detection. The results showed that cycloartobiloxanthone had comparable cytotoxic activity to cisplatin and etoposide 

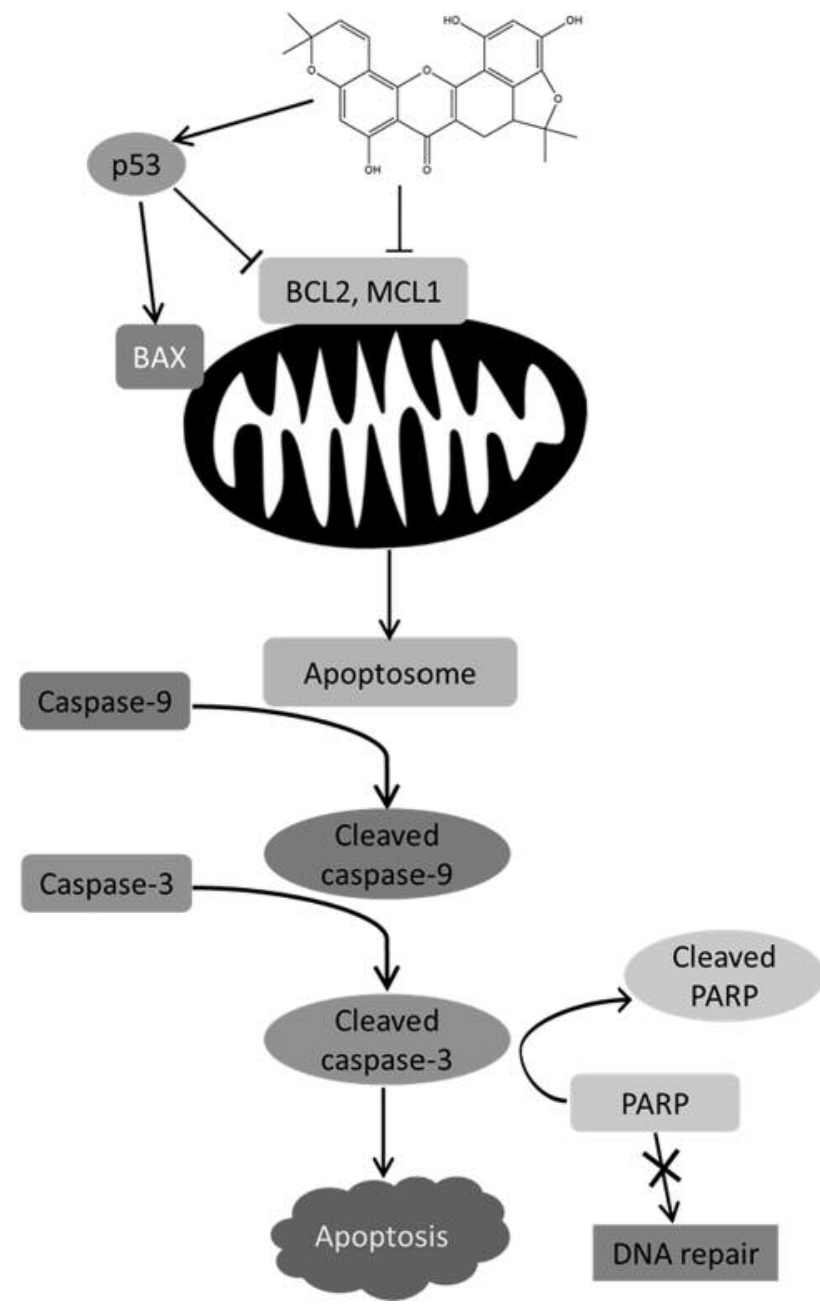

Figure 6. Possible mechanism of action of cycloartobiloxanthone-induced apoptosis. Once cycloartobiloxanthone enters the cancer cell, it activates p53 and inhibits anti-apoptotic B-cell lymphoma 2 (BCL2) family proteins, $B C L 2$ and myeloid cell leukemia 1 (MCL1), resulting in up-regulation of pro-apoptotic BCL2 family protein, BCL2-associated X protein (BAX). Alteration of the balance between these pro- and anti-apoptotic proteins triggers mitochondria-mediated apoptotic pathway through the caspase cascade. Cytochrome c released from mitochondria and apoptotic protease activating factor 1 protein forms the apoptosome with activated caspase9 (cleavage form). Cleaved caspase-9 then cleaves caspase-3, which is a key caspase that triggers apoptotic processes, one of which is inhibition of DNA repair by poly (ADP-ribose) polymerase (PARP) activity.

(Figure 4). Moreover, human keratinocytes, HaCaT cells, were used to evaluate the effect of cycloartobiloxanthone on non-cancerous cells. The results showed that $50 \mu \mathrm{M}$ cycloartobiloxanthone significantly reduced $\mathrm{HaCaT}$ cell viability to a degree comparable to that of $50 \mu \mathrm{M}$ cisplatin, and $50 \mu \mathrm{M}$ etoposide (Figure 4A).
Cycloartobiloxanthone induces apoptosis via mitochondriadependent pathway. To investigate the mechanism of cycloartobiloxanthone-induced apoptosis, apoptotic-related proteins were determined by western blot analysis. Human lung cancer $\mathrm{H} 460$ cells were treated with $0-50 \mu \mathrm{M}$ for $24 \mathrm{~h}$ and p53, along with pro- and anti-apoptotic proteins related to mitochondria-mediated apoptosis were evaluated. In response to treatment with cycloartobiloxanthone, p53 was found to be activated and the cellular level of pro-apoptotic proteins was increased, while expression of anti-apoptotic proteins was suppressed. Pro-apoptotic protein BAX was up-regulated, while anti-apoptotic proteins MCL1 and BCL2 were downregulated in cells treated with cycloartobiloxanthone (Figure 5). In addition, the mitochondria-dependent apoptosis pathwayspecific caspase- 9 was found to be activated, and apoptotic markers, caspase- 3 and PARP were subsequently cleaved. The results indicated that cycloartobiloxanthone mediated apoptosis of lung cancer cells by increasing the ratio of pro- to antiapoptotic proteins leading to death by mitochondria-dependent pathway.

\section{Discussion}

New drugs for cancer therapy are urgently needed, especially for lung cancer due to the limited efficacy obtained from the currently available therapy, and the 5-year survival rate of patients with lung cancer is low (8). Pharmacologically active compounds from natural products have great potential to be developed for anticancer therapies with an expectation of better efficacy and lower toxicity (9). We have demonstrated herein for the first time that cycloartobiloxanthone, a plantderived compound, has a promising ability to kill lung cancer cells through apoptosis (Figures 2 and 3) at similar potency to the currently used standard drugs.

Apoptosis, or programmed cell death, can be caused by two major mechanisms: the extrinsic pathway via death receptors and the intrinsic pathway via mitochondrial pathways. The intrinsic apoptotic mechanism is very important for cancer inhibition and can be triggered by most anticancer drugs (10). Protein analysis revealed that cycloartobiloxanthone triggered mitochondria-mediated apoptosis via p53 induction, which in turn down-regulated anti-apoptotic BCL2 and MCL1 levels and induced that of pro-apoptotic BAX protein (Figure 6). In apoptosis, the reduction of BCL2 and MCL1, and the induction of BAX leads to the release of pro-apoptotic factors from mitochondria and activates caspase- 9 as a downstream target. Activated caspase- 9 activates the caspase- 3 cascade, inhibits DNA repair, and accomplishes apoptosis $(11,12)$. Together with the fact that many cancer cells depend upon BCL2 and other anti-apoptotic proteins for their survival, the approach of molecular therapies that target BCL2 protein, such as cycloartobiloxanthone, could have promising activity in 
killing many types of cancer cells. Several BCL2 antagonists such as ABT-263 (Abbott Laboratories, Worcester, MA, USA), Obatoclax (Gemin X, Malvern, PA, USA), and Oblimersen (Genta, Berkeley Heights, NJ, USA) are currently under evaluation in the clinical phase for the treatment of lung cancer (11). Cycloartobiloxanthone, which has the ability to suppress anti-apoptotic proteins of the BCL2 family, may become a promising candidate for the treatment of lung cancer. Increasing evidence has indicated the role of antiapoptotic MCL1 as an important protein in inhibition of cell apoptosis and anoikis $(13,14)$. In particular, non-small cell lung cancer cells taken from patients have been shown to have elevated MCL1 protein levels compared to the surrounding lung cells, and enhanced MCL1 expression protects cancer cells from various apoptotic stimuli (15). Amplification and overexpression of BCL2 occurs in many malignancies, including small cell lung carcinoma, and impairs intrinsic apoptotic signaling (16). Moreover, the overexpression of BCL2 has been showed to inhibit cisplatininduced cell death in non-small cell lung cancer H460 cells (17). The findings of the current study indicate that, by targeting MCL1 and BCL2 proteins, cycloartobiloxanthone may have utility in the treatment of lung cancer. However, other underlying activity against cancer cells and toxicity test of this compound itself should be further investigated.

\section{Conclusion}

This study revealed that cycloartobiloxanthone has anticancer activity against several types of lung cancer cells via induction of apoptosis by suppressing expression of anti-apoptotic BCL2 and MCL1 proteins and increasing that of pro-apoptotic BAX protein due to increased p53 protein expression. Understanding the mechanisms of action of this compound may benefit its further development for anticancer treatment.

\section{Conflict of Interest}

The Authors declare no conflict of interest in regard to this study.

\section{Acknowledgements}

This research was supported by a grant for International Research Integration: Chula Research Scholar, Ratchadaphiseksomphot Endowment Fund.

\section{References}

1 Fitzmaurice C, Allen C, Barber RM, Barregard L, Bhutta ZA, Brenner H, and Global Burden of Disease Cancer Collaboration: Global, regional, and national cancer incidence, mortality, years of life lost, years lived with disability, and disability adjusted life-years for 32 cancer groups, 1990 to 2015. A systematic analysis for the global burden of disease study. JAMA Oncol 3: 524-548, 2017.
2 Shen D, Pouliot LM, Hall MD and Gottesman MM: Cisplatin resistance: A cellular self-defense mechanism resulting from multiple epigenetic and genetic changes. Pharmacol Rev 64: 706-721, 2012.

3 Tseng CY, Lin CH, Wu LY, Wang JS, Chung MC, Chang JF and Chao MW: Potential combinational anti-cancer therapy in nonsmall cell lung cancer with traditional Chinese medicine SunBai-Pi extract and cisplatin. PLoS ONE 11: e0155469, 2016.

4 Zhang L, Ren B, Zhang J, Liu L, Liu J, Jiang G, Li M, Ding Y and Li W: Anti-tumor effect of Scutellaria barbata D. Don extracts on ovarian cancer and its phytochemicals characterisation. J Ethnopharmacol 206: 184-192, 2017.

5 Sritularak B, Tantituvanont A, Chanvorachote P, Meksawan K, MiyamotoT, Kohno Y and Likhitwitayawuid K: Flavonoids with free radical-scavenging activity and nitric oxide inhibitory effect from the stem bark of Artocarpus gomezianus. J Med Plants Res 4: 387-392, 2010.

6 Boonphong B, Baramee A, Kittakoop P and Puangsombat P: Antitubercular and antiplasmodial prenylated flavones from the roots of Artocarpus altilis. Chiang Mai J Sci 34: 339-344, 2007.

7 Ren Y, Kardono LBS, Riswan S, Chai H, Farnsworth NR, Soejarto DD, Carcache de Blanco EJ and Kinghorn AD: Cytotoxic and NF-kB inhibitory constituents of Artocarpus rigida. J Nat Prod 73: 949-955, 2010.

8 American Cancer Society: Cancer Facts \& Figures 2017. Atlanta: American Cancer Society, 2017.

9 Greenwell M and Rahman PKSM: Medicinal plants: Their use in anticancer treatment. Int J Pharm Sci Res 6: 4103-4112, 2015.

10 Elmore S: Apoptosis: A Review of Programmed Cell Death. Toxicol Pathol 35: 495-516, 2007.

11 Pandey MK, Prasad S, Tyagi AK, Deb L, Huang J, Karelia DN, Amin SG and Aggarwal BB: Targeting Cell Survival Proteins for Cancer Cell Death. Pharmaceuticals 9: 11, 2016.

12 Brentnall M, Rodriguez-Menocal L, Ladron De Guevara R, Cepero E and Boise LH: Caspase-9, caspase-3 and caspase-7 have distinct roles during intrinsic apoptosis. BMC Cell Biol 14: 32, 2013.

13 Moulding DA, Giles RV, Spiller DG, White MRH, Tidd DM and Edwards SW: Apoptosis is rapidly triggered by antisense depletion of MCL-1 in differentiating U937 cells. Blood 96: 1756-1763, 2000.

14 Woods NT, Yamaguchi H, Lee FY, Bhalla KN and Wang HG: Anoikis, initiated by MCL-1 degradation and BIM induction, is deregulated during oncogenesis. Cancer Res 67: 10744-10752, 2007.

15 Ikegaki N, Katsumata M and Minna J: Expression of BCL-2 in small cell lung carcinoma cells. Cancer Res 54: 6-8, 1994.

16 Song L, Coppola D, Livingston S, Cress D and Haura EB: MCL-1 regulates survival and sensitivity to diverse apoptotic stimuli in human non-small cell lung cancer cells. Cancer Biol Ther 4: 267-276, 2005.

17 Chanvorachote P, Nimmannit U, Stehlik C, Wang L, Ongpipatanakul B and Rojanakul Y: Nitric oxide regulates cell sensitivity to cisplatin-induced apoptosis through $S$-nitrosylation and inhibition of BCL-2 ubiquitination. Cancer Res 66: 6353$6360,2006$.

Received September 4, 2017

Revised October 10, 2017

Accepted October 12, 2017 